\title{
Abordagem Ergonômica de Avaliação de Websites no âmbito da Educação à Distância
}

\author{
Doris Simone Reitz, M.Sc.* \\ Fernando Gonçalves Amaral, Dr. * \\ Walter de Abreu Cybis, Dr.**
}

\section{Resumo}

As instituições de ensino estão em busca de conhecimentos sobre suas necessidades e oportunidades para a aprendizagem à distância. Para tanto, verifica-se a necessidade de cuidados relativos à qualidade das interações neste âmbito disponibilizadas na web. Este estudo apresenta a aplicação de uma metodologia de avaliação qualitativa para medir a usabilidade de websites de Educação à Distância $(\mathrm{EaD})$ na tecnologia de Web Based Training (WBT). O método de inspeção é baseado em recomendações ergonômicas específicas ao ambiente de $\mathrm{EaD}$, compiladas conforme os Critérios Ergonômicos (CE) e Componentes de Interação Homem-Computador. Os resultados são apresentados sob forma de recomendações ergonômicas para o reprojeto do website, visando a melhoria da qualidade de interação do usuário com a interface.

Palavras-chave: critérios ergonômicos, usabilidade, educação à distância, websites.

\begin{abstract}
Learning Institutions are in search for the necessary knowledge to meet their needs and expectations for distance learning. For that, we verify the need of taking care in relation to the interactive quality distributed in the web in this area. This study presents the application of a qualitative methodology evaluation to measure the usability of Distance Education Websites supported by Web Based Training (WBT) technology. The screening method of inspection is based on specific ergonomic guidelines for Distance Education Environments compiled by Ergonomic Criteria and Human Computer Interaction Components. The results are presented by means of ergonomic recommendation for the reproject of the website to aim better quality of interaction between user and the interface.
\end{abstract}

Keywords: ergonomic criteria, usability, distance education, websites.

\section{Introdução}

Nos dias atuais, as aulas tradicionais com base em modelos presenciais, vêm sendo convertidas em ambientes de aprendizagem online, nas quais os planos de estudo e diversos materiais de aprendizado como leituras e tarefas, estão disponíveis ao clicar

\footnotetext{
* Programa de Pós-graduação em Engenharia de Produção - Ergonomia

Universidade Federal do Rio Grande do Sul (UFRGS) - CEP: 90040-020 - Porto Alegre - RS

e-mail: amaral@producao.ufrgs.br; doris.r@globo.com

*** Instituto de Informática e Estatística (INE)

Universidade Federal de Santa Catarina (UFSC) - Campus Universitário - Trindade - CEP 88040-900 -

Florianópolis - SC e-mail: cybis@inf.ufsc.br

V.2 $\mathrm{N}^{\circ} 2$, Novembro, 2004
} 
de um mouse. Assim, novas opções tecnológicas estão mudando a natureza do ensino e as próprias relações de ensino e aprendizagem, nas quais os professores tornam-se facilitadores e mentores no desenvolvimento de modelos de ensino, ao invés de simples orientadores educacionais. Os alunos, por sua vez, também experimentam a transformação passando de receptores passivos para participantes ativos em um ambiente de aprendizagem, sendo que as interações são o centro desta revolução (MCNEIL et al., 2000).

Nesse contexto, a World Wide Web (WWW) se apresenta como uma tecnologia capaz de atender às expectativas dos pesquisadores na área de Educação à Distância, proporcionando soluções para o problema do oferecimento de educação e capacitação em larga escala. Isto, a custos mais acessíveis que os atuais e permitindo a publicação de material didático, aplicação de tutoriais, de provas e testes, a comunicação com os estudantes e aulas à distância.

No entanto, a maioria dos cursos à distância é desenvolvida sem que se considere a ergonomia em seus sistemas produtivos, impossibilitando garantir a qualidade de interação dos usuários com a interface. Segundo Moraes e Mont'Alvão (2000), a Ergonomia como ciência trata de desenvolver conhecimentos sobre as capacidades, limites e outras características do desempenho humano que se relacionam com o projeto de interfaces, entre indivíduos e outros componentes do sistema. Como prática, a Ergonomia compreende a aplicação de tecnologia da interface homem-sistema ao projeto ou modificações de sistemas, para aumentar a segurança, conforto e eficiência do sistema e da qualidade de vida.

Desde meados dos anos 80, normas oficiais e publicações de recomendações de uso de interfaces tipo software e Interação Homem-Computador (IHC) têm crescido em importância, na medida em que o uso dos computadores tornou-se persuasivo no local de trabalho, bem como em outros ambientes. Os benefícios substanciais, tanto para o usuário final como para o empregador, com o uso de normas e recomendações relativas ao uso da interface, podem resultar no aumento da produtividade, na redução do stress mental e físico, na redução dos gastos com treinamento, no aperfeiçoamento da interoperacionalidade sistema-usuário através de aplicações e, ainda, no aperfeiçoamento da qualidade e da estética dos produtos (REED et al., 1999).

A fim de tornar efetivo o uso da tecnologia web, os projetistas de websites não deveriam proporcionar somente um conteúdo que seja relevante, mas sim apresentá-lo de forma a resultar em uma experiência efetiva, proveitosa e satisfatória para o usuário nas suas tarefas específicas. Esta experiência do usuário recebeu a definição de "usabilidade" (ISO, 1993).

A experiência da interação dos alunos com a interface na web, não pode ser considerada somente o simples clicar de um mouse, pois há fatores humanos envolvidos. Em salas de aula tradicionais, o professor auxilia e é ator no processo de ensino e de aprendizagem; já na web, o fator humano envolvido é considerado a usabilidade.

Conforme Mayhew (1992), há fatores que são particularmente problemáticos para a usabilidade de websites. Entre estes: o grande volume de texto publicado na web, o qual afeta o desempenho na leitura; a procura por informações, a qual é afetada pela falta de organização; a incompreensibilidade dos hyperlinks (imagens e textos); a presença ou ausência de dispositivos de pesquisa e a qualidade da navegação (SHNEIDERMANN, 1997).

A usabilidade avalia a qualidade da interação do usuário com a interface. Conforme Cybis (2000), os efeitos provocados por problemas de usabilidade são experimentados diretamente pelo usuário e indiretamente sobre a sua tarefa, acarretando perda de tempo, erros ou perda de informações. Eles podem apresentar-se como uma 2 V.2 No2, Novembro, 2004 
sobrecarga perceptiva, por exemplo, dificuldades de leitura, sobrecarga cognitiva (desorientação ou hesitação), ou ainda, uma sobrecarga física (dificuldade de acionamento). A usabilidade também visa diminuir custos, o que pode representar uma vantagem competitiva. Problemas de usabilidade como: dificuldade em encontrar a informação desejada, em retornar a uma página anteriormente visitada e o uso excessivo de cores, podem gerar confusão visual, retardar, prejudicar e, até mesmo, impedir a execução de uma tarefa.

Estes problemas adicionam um custo significativo, quando seus efeitos são medidos através de todos os usuários. Dessa forma, constata-se o retorno potencial que pode ser alcançado pelo aumento da usabilidade de websites. Portanto, faz-se necessário avaliar a usabilidade, no intuito de produzir constantes melhorias na qualidade de interação dos alunos com o website e, desta forma, melhorar as condições de aprendizagem.

O objetivo deste estudo é de proporcionar diretrizes ergonômicas para websites de EaD. Além disso, indiretamente, contribuir com o desenvolvimento de ferramentas baseadas em recomendações ergonômicas para a avaliação da usabilidade de websites de Web Based Training (WBT), e ainda, avaliar um website de $\mathrm{EaD}$, empregando uma metodologia de verificação de usabilidade ergonômica e participativa. Assim, com base nesta avaliação, propor melhorias para o website.

O método de pesquisa utilizado no trabalho foi o de um Estudo de Caso com características descritivas. O estudo foi desenvolvido através da aplicação de uma técnica de avaliação de usabilidade, inspirada em uma Intervenção Ergonômica.

\section{Metodologia}

O Web-Based Training (WBT) ou Treinamento Baseado na web emprega a Internet ou Intranet para disponibilizar a instrução. Embora seja definido como "baseado" na web, muitas ferramentas usadas com este tipo de tecnologia educacional não utilizam o ambiente da web, como por exemplo, o Protocolo de Transferência de Arquivos (FTP), Usenet, correio da Internet, Telnet, Listservs ou mesmo as salas de bate-papo. O WBT pode ser utilizado de duas formas, como suplemento a um curso regular (uma forma de CAI - Computer Assisted Instruction), ou para substituir cursos que foram ou teriam sido oferecidos em salas de aula regulares. Desta forma, tais cursos são referidos como Cursos Baseados na Web, Cyber Courses ou Cursos Virtuais. Nestas situações, o WBT freqüentemente permite aos alunos trabalharem em seu próprio ritmo (BELANGER; JORDAN, 2000).

Assim, o conteúdo educacional pode ser distribuído de forma síncrona e assíncrona em diferentes níveis de complexidade pela Internet. Alguns dos diferentes tipos de alternativas de WBT (BARRON et al., 1999 apud BELANGER; JORDAN, 2000) são a Correspondência Assíncrona; a Colaboração Síncrona; Web Enhanced Courses; Web Managed Courses; Web Delivered Courses e Hybrid Delivery Systems.

A Técnica de Avaliação de Co-Inspeção Ergonômica descrita é considerada especificamente para inspecionar de forma ergonômica websites de cunho educacional. Esta é oriunda de outra similar denominada ErgoCoin. Tal técnica foi elaborada por Cybis et. al. (2002) em colaboração com o INRIA (França), que em sua origem era voltada para a avaliação de websites de comércio eletrônico, especializados na venda direta de produtos ao consumidor.

Conforme Cybis et al. (2002), a Técnica de Avaliação de Co-Inspeção Ergonômica é definida como uma inspeção de características ergonômicas para websites, as quais são divididas em qualidades (atributos) e componentes de interação, inspecionados através de checklists. A denominação de Co-inspeção, ou seja, avaliação 
participativa, é dada ao fato dela basear-se tanto na inspeção do avaliador, como também nas informações obtidas pelos usuários e projetistas; ambos da perspectiva de descrição como também de avaliação do website.

Os métodos de inspeção diferenciam-se na forma pela qual o julgamento do avaliador é realizado, e ainda, pelo próprio critério de avaliação, que são as bases para tais julgamentos. Assim, as informações vitais relacionadas ao contexto real e prescrito de operação do website são obtidas através de usuários reais e dos projetistas, exigindo para tal que os websites a serem avaliados estejam disponíveis na web e possuam usuários reais e projetistas.

A técnica utiliza-se de entrevistas e do método de inspeção para a coleta de dados e informações. Estas últimas, obtidas por meio das entrevistas, estão relacionadas às ações dos usuários e à satisfação quanto aos componentes interativos do website em avaliação. De outra forma, também são consideradas como um caminho para estabelecer uma comparação entre o cenário de uso descrito pelo usuário (real) e o planejado pelo projetista (prescrito).

Após definir o cenário de uso, ou seja, o conjunto de páginas a ser inspecionado, dá-se início à inspeção propriamente dita. Esta se fundamenta no julgamento do avaliador, independentemente da participação do usuário. O método de inspeção é baseado no conhecimento ergonômico organizado por Critérios Ergonômicos e Componentes de Interação que são inspecionados por meio de Checklists. Nesta etapa é aplicado um conjunto de questões ergonômicas definidas pelas tarefas, atividades e componentes, que desempenham um papel realmente importante no website. Os resultados são apresentados por meio de relatórios com as recomendações ergonômicas para o reprojeto do website, visando a melhoria da qualidade de interação dos usuários com a interface.

As recomendações ergonômicas foram obtidas pela compilação das recomendações definidas por Leulier, Bastien e Scapin (1998) pesquisadores do INRIA (Institut National de Recherche en Informatique et en Automatique - França), as quais foram complementadas com mais informações de diferentes estudos realizados por Scapin et al. (2000); pelos Componentes de Interação definidos por Cybis (1997) e por algumas recomendações extraídas da TICESE - Técnica de Inspeção de Conformidade Ergonômica de Software Educacional, definida por Gamez (1998). Estas recomendações foram especializadas para o ambiente de EaD pelo autor deste trabalho, para aplicação neste Estudo de Caso. Elas formam o conjunto de recomendações ergonômicas que define os padrões de apresentação e de comportamento para os componentes de interação da interface de websites de EaD na tecnologia de WBT, estabelecendo assim a base de dados utilizada na aplicação do método de inspeção.

A aplicação da técnica de avaliação propriamente dita, inicia-se com a descrição detalhada do objeto de análise, ou seja, do website de EaD. Na descrição deve obrigatoriamente constar: o endereço (URL) na web, a definiçãa e os objetivos do curso, bem como os responsáveis pelo projeto.

A seguir é escolhido um grupo ou uma amostra de usuários reais, que estejam cursando ou já tenham concluído o curso em avaliação, devido ao fato de já possuírem experiência quanto às ações requeridas na interação com o website, para o alcance de suas expectativas. Além disso, por estarem também aptos a identificar alguns problemas de usabilidade, decorrentes de necessidades não supridas ou dificuldades eventualmente encontradas.

A metodologia da técnica proposta é formada por duas etapas principais: a CoDescrição e a Inspeção Avaliativa. O fluxograma da figura 1 ilustra os procedimentos da técnica proposta. 


\section{Resultados}

O endereço na web (URL) do website avaliado está disponível em www.teknologia.com.br. Neste endereço pode-se ter acesso ao curso intitulado "Curso Online de Base de Dados na Gestão Empresarial". O curso utiliza a ferramenta Microsoft Access como o Sistema Gerenciador de Base de Dados, permitindo realizar na prática os conceitos teóricos abordados no curso. O modelo pedagógico utilizado como base para o aprendizado é construtivista.

O público alvo das entrevistas na etapa de Co-Descrição foi constituído por três projetistas e sete alunos do curso. Os projetistas entrevistados foram um autor e dois webmasters; e os usuários foram alunos que estavam cursando ou que já haviam concluído o curso.

Os checklists Global, da Homepage e das páginas web do Cenário de Uso foram configurados manualmente somente com as questões aplicáveis. Estas foram definidas pelos componentes e atributos identificados respectivamente nos Formulários de Descrição Global, da Homepage e Local das páginas web do Cenário de Uso. Todas as questões na base de dados foram indexadas conforme componentes e critérios ergonômicos.

A partir de 255 componentes identificados como presentes no website, na homepage e nas páginas do Cenário de Uso na etapa de Co-Descrição, foram gerados 13 checklists pelos quais inspecionou-se 910 questões aplicáveis. Os checklists inspecionados foram: Global, Homepage, Conteúdo, Inscrição, Inscrição - Módulo I, Política de Privacidade, Formulário de Inscrição, Confira sua Inscrição, Aulas - Login, Aulas - Lista, Aulas - Conteúdo Programático da aula 8 parte 1, Aulas - Exercício aula 1 parte 5, e ainda, Aulas - Prova Final aula 2 parte 5.

As informações fornecidas pelos usuários e projetistas foram organizadas para a elaboração de um pré-diagnóstico dos problemas de usabilidade e apresentaram os seguintes resultados:

As perspectivas dos projetistas quanto ao perfil dos usuários para qual o website foi projetado, ou seja, o público alvo, foi considerado compatível com o perfil encontrado diretamente através dos usuários reais;

As nomenclaturas e representações do ponto de vista dos usuários e dos projetistas não apresentaram indicações de possíveis problemas de usabilidade;

O Cenário de Uso escolhido foi o "real", ou seja, o descrito pelos usuários, considerando-se também o índice de $50 \%$ para estabelecer quais páginas necessitaram de inspeção. Nesta etapa, foram consideradas algumas sugestões de melhorias sobre aspectos gerais do website obtidas através dos usuários. 
Descrição Assistida Local

Descrição Assistida Global e da Homepage

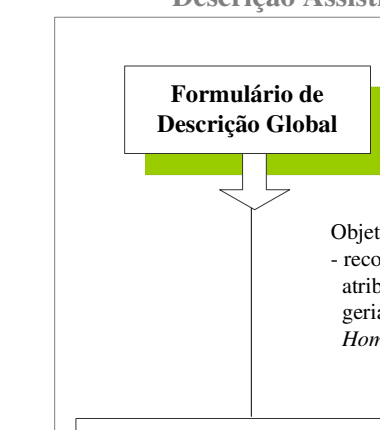

Tabela de características atributos do Website

relacionados aos

Aspectos Ergonômicos

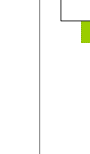

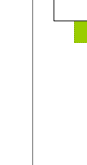

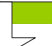

\section{Aspectos Ergonomicos}

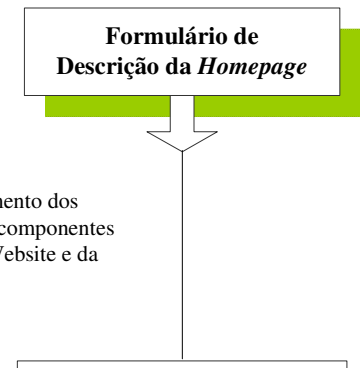

Tabela de características e atributos da Homepage

relacionados aos

Aspectos Ergonômicos

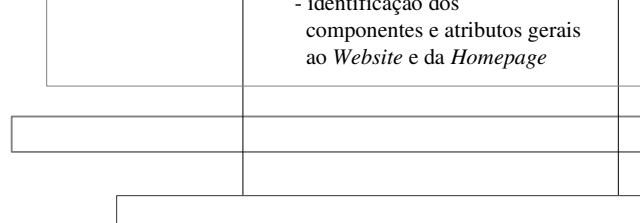

\section{E}

ntrevistas com os projetistas
Entrevistas com os usuários

(1)

5

Objetivos:

- identificação do perfil dos usuários

- pré-diagnóstico de problemas

de usabilidade

- identificação das tarefas principais de interação: cenário "real" x "prescrito"

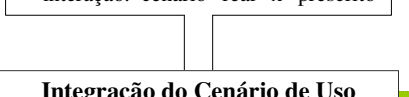

Integração do Cenário de Uso

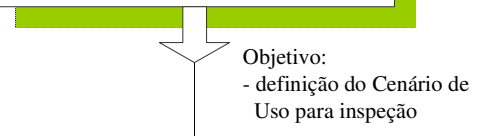

Formulário de Descrição Local

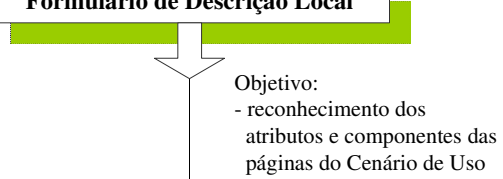

páginas do Cenário de Uso

Tabela de características e atributos das páginas $w e b$ relacionados aos Aspectos Ergonômicos
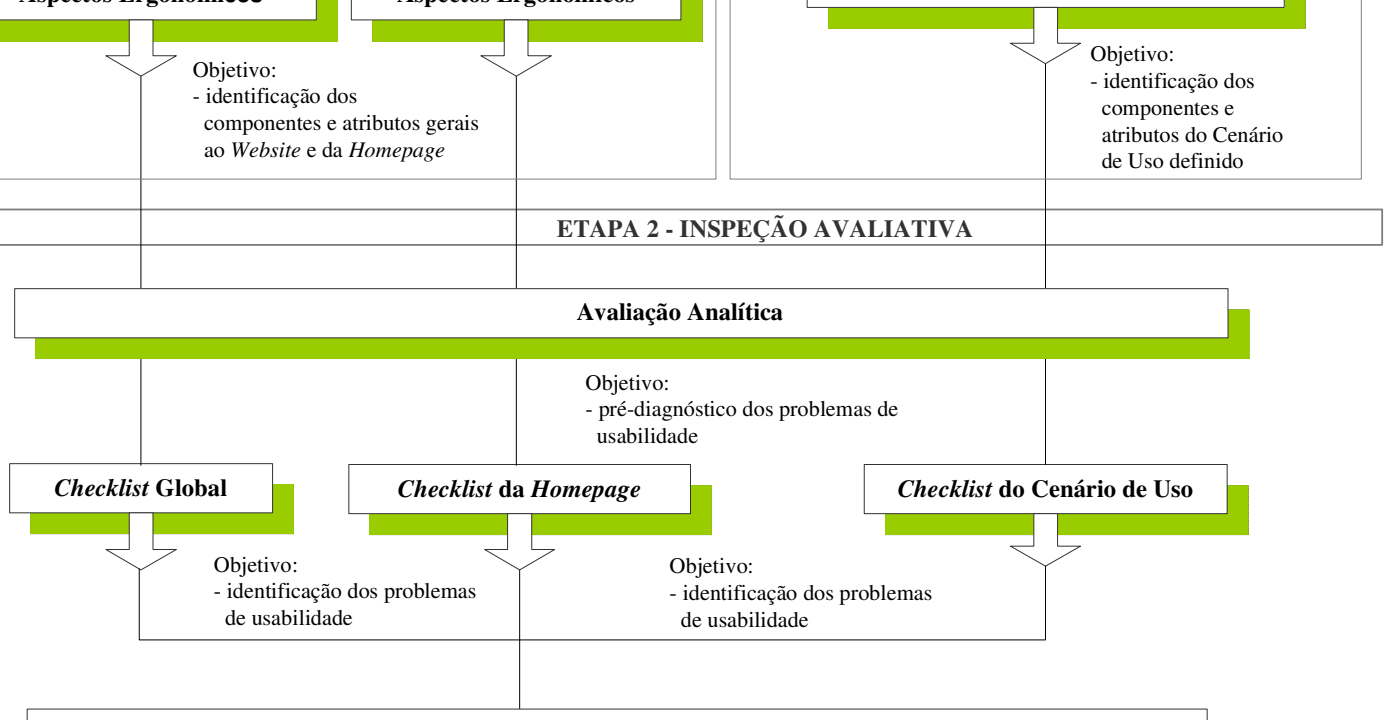

Os Relatórios Finais podem ser apresentados com as recomendações ergonômicas para:

- os problemas relacionados aos principais cenários e tarefas definidas pelo usuário ou pelo projetista

- as questões respondidas para uma página da Web específica (URL)

- os problemas relacionados a um critério ergonômico específico

Também podem ser apresentados dados sobre os critérios ergonômicos e características/componentes mais desrespeitados.

\section{Figura 1 - Fluxograma dos Procedimentos da Técnica}


O registro dos problemas de usabilidade encontrados no website por meio dos checklists na inspeção avaliativa foi estimado pela descrição textual do problema. Assim, os Relatórios Finais foram elaborados considerando-se as questões inspecionadas para cada página web específica (URL). Os resultados são apresentados em forma de recomendação ergonômica descrevendo o componente e o critério ergonômico relativo ao problema.

\begin{tabular}{|c|c|}
\hline $\begin{array}{l}\text { Componente/ } \\
\text { Característica }\end{array}$ & Recomendação Ergonômica a ser atendida \\
\hline $\begin{array}{l}\text { Grande número de } \\
\text { páginas }\end{array}$ & $\begin{array}{l}\text { Presteza } \\
\text { Em grandes sites usar um mapa que possibilite a orientação do usuário permitindo a ele saber onde se } \\
\text { encontra e onde pode ir. }\end{array}$ \\
\hline $\begin{array}{l}\text { Hierarquia de } \\
\text { subtítulo }\end{array}$ & $\begin{array}{l}\text { Homogeneidade / Coerência } \\
\text { Manter os cabeçalhos de forma similar para indicar as mesmas divisões de informações ao longo das } \\
\text { páginas do site (ex.: subtítulo } 1 \text { para categorias, subtítulo } 2 \text { para subcategorias). }\end{array}$ \\
\hline & $\begin{array}{l}\text { Presteza } \\
\text { Informar aos usuários sobre tamanho, tempo de carregamento e requisitos de plataforma necessários } \\
\text { para visualizar arquivos de vídeo e animações. }\end{array}$ \\
\hline Animação & $\begin{array}{l}\text { Presteza } \\
\text { Informar aos usuários sobre a necessidade de aplicações de apoio para vídeo e animações, sobre como } \\
\text { configurar seus browsers para este uso e sobre como fazer o download dos arquivos de vídeo e } \\
\text { animação. }\end{array}$ \\
\hline Plug-in & $\begin{array}{l}\text { Presteza } \\
\text { Informar aos usuários, na própria página onde um recurso especial é executado (ex. vídeo, música) ou } \\
\text { em uma página auxiliar, sobre quais utilitários de apoio (plug-in) são requeridos para executá-lo, } \\
\text { como eles trabalham, como acessá-los, como carregá-los, como descompactá-los, onde armazená-los } \\
\text { e quais os passos para configurar o navegador para seu uso. }\end{array}$ \\
\hline Mensagem de erro & $\begin{array}{l}\text { Qualidade das Mensagens de Erro } \\
\text { Informar ao usuário a causa exata do problema nas mensagens de erro e os passos a serem seguidos } \\
\text { para solucioná-lo. }\end{array}$ \\
\hline \multirow{3}{*}{$\begin{array}{l}\text { Recursos de } \\
\text { navegação }\end{array}$} & $\begin{array}{l}\text { Ações Mínimas } \\
\text { Cada uma das páginas do site precisa ter um link para a página principal. }\end{array}$ \\
\hline & $\begin{array}{l}\text { Presteza } \\
\text { A apresentação da estrutura de navegação do site precisa conter indicações visuais capazes de situar o } \\
\text { usuário em relação a sua posição atual nesta estrutura e como ele pode nela se movimentar. }\end{array}$ \\
\hline & $\begin{array}{l}\text { Presteza } \\
\text { Proporcionar um índice/sumário do site prontamente acessível ao usuário. }\end{array}$ \\
\hline $\begin{array}{l}\text { Estrutura de } \\
\text { navegação }\end{array}$ & $\begin{array}{l}\text { Ações Mínimas } \\
\text { As páginas do site precisam ser organizadas permitindo um acesso rápido (não mais do que três } \\
\text { passagens a partir da homepage) às informações mais utilizadas. }\end{array}$ \\
\hline Link & $\begin{array}{l}\text { Presteza } \\
\text { Verificar se a ajuda geral e específica às páginas está sempre disponível ao longo do site. }\end{array}$ \\
\hline
\end{tabular}

\section{Quadro 1 - Recomendações Ergonômicas gerais ao Website}




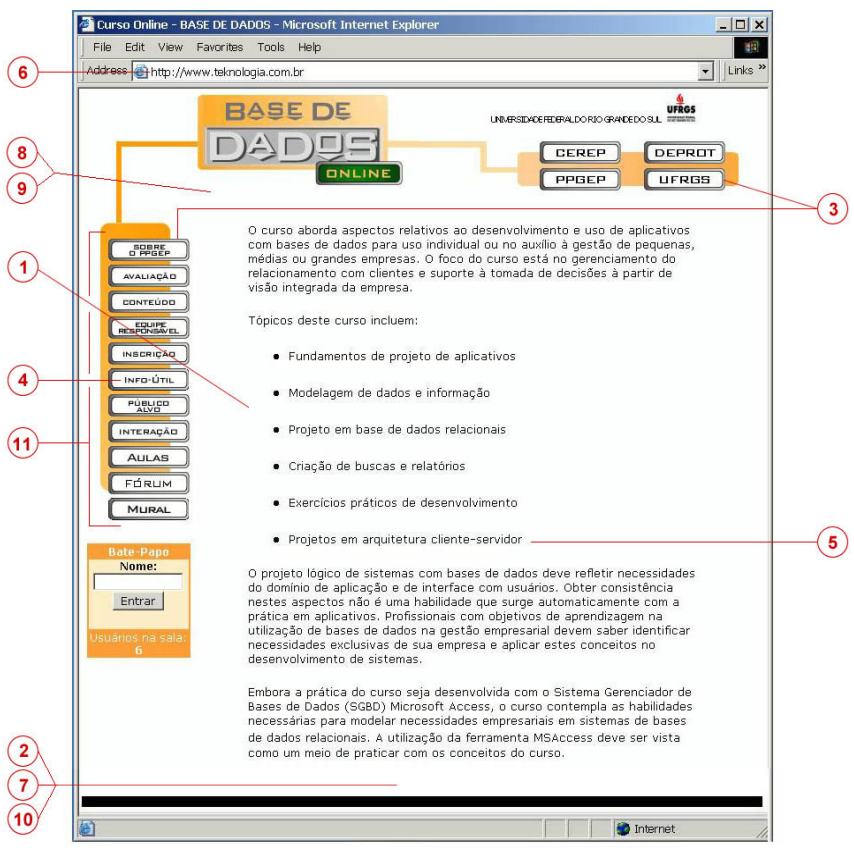

Figura 2 - Ilustração da Homepage

Fonte: Curso Base de Dados Online. Disponível em http://www.teknologia.com.br. Acessado em 03/2003.

\begin{tabular}{|c|c|c|}
\hline $\begin{array}{l}\text { Componente/ } \\
\text { Característica }\end{array}$ & $*$ & Recomendação Ergonômica a ser atendida \\
\hline Lista & 1 & $\begin{array}{l}\text { Agrupamento / Distinção de Itens por Formato } \\
\text { Concisão } \\
\text { As listas que contêm mais de } 5 \text { itens devem estar divididas em grupos de itens significativos. }\end{array}$ \\
\hline $\begin{array}{l}\text { Recurso de } \\
\text { navegação }\end{array}$ & 2 & $\begin{array}{l}\text { Presteza } \\
\text { Nas páginas ou frames que necessitam de rolagem, devem existir conjuntos de links localizados, tanto no topo } \\
\text { como na parte inferior destas páginas (na inexistência de um frame de navegação permanente). }\end{array}$ \\
\hline Link gráfico & 3 & $\begin{array}{l}\text { Significado dos Códigos e Denominações } \\
\text { As categorias de links (navegação, ajuda, comandos, etc.) representadas graficamente (ícones ou figuras) } \\
\text { precisam ser claras e diferenciáveis entre si. }\end{array}$ \\
\hline Abreviatura & 4 & $\begin{array}{l}\text { Legibilidade } \\
\text { Evitar o uso de abreviaturas nos menus, opções de menu, título das caixas de diálogo, e mostradores de dados. }\end{array}$ \\
\hline Termo técnico & 5 & $\begin{array}{l}\text { Presteza } \\
\text { Significado dos Códigos e Denominações } \\
\text { Proporcionar definições ou descrições para os termos técnicos ou jargões empregados no site. }\end{array}$ \\
\hline $\begin{array}{l}\text { Endereço } \\
\text { Eletrônico }\end{array}$ & 6 & $\begin{array}{l}\text { Significado dos Códigos e Denominações } \\
\text { A URL da página precisa, de alguma maneira, ser compreensível para as pessoas. }\end{array}$ \\
\hline \multirow{4}{*}{ Informação } & 7 & $\begin{array}{l}\text { Presteza } \\
\text { Na página de acesso ao site precisam existir informações, de preferência no rodapé, sobre o autor do site, sobre } \\
\text { a pessoa que o mantém (e-mail), sua última atualização, com que freqüência são feitas atualizaç̃oes, a } \\
\text { empresa/instituição responsável, os termos do copyright e as instruções úteis para o acesso ao site. }\end{array}$ \\
\hline & 8 & $\begin{array}{l}\text { Presteza } \\
\text { As páginas precisam conter um título claro e informações contextuais indicando a posição do usuário no site. }\end{array}$ \\
\hline & 9 & $\begin{array}{l}\text { Presteza } \\
\text { Colocar título na barra de título em cada página. }\end{array}$ \\
\hline & 10 & $\begin{array}{l}\text { Presteza } \\
\text { Colocar o endereço da página em seu rodapé. }\end{array}$ \\
\hline Objetos de controle & 11 & $\begin{array}{l}\text { Feedback Imediato } \\
\text { O sistema precisa fornecer feedback sobre as mudanças de atributos dos objetos de interação, ou seja, ao } \\
\text { selecionar um botão ou ícone correspondente a esta opção; este apresenta mudança de estado, entre visitado e } \\
\text { não visitado. }\end{array}$ \\
\hline
\end{tabular}

* = indicação da recomendação ergonômica apresentada na ilustração da página Quadro 2 - Recomendações Ergonômicas para a Homepage 


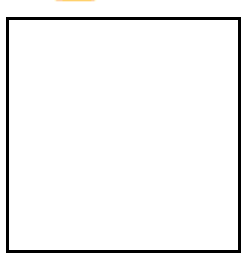

Figura 3 - Ilustração da página de Conteúdo

Fonte: Curso Base de Dados Online. Disponível em http://www.teknologia.com.br. Acessado em 03/2003.

\begin{tabular}{|c|c|c|}
\hline $\begin{array}{l}\text { Componente/ } \\
\text { Característica }\end{array}$ & $*$ & Recomendação Ergonômica a ser atendida \\
\hline Lista & 1 & $\begin{array}{l}\text { Agrupamento/Distinção de Itens por Formato } \\
\text { Concisão } \\
\text { As listas que contêm mais de } 5 \text { itens precisam estar divididas em grupos de itens significativos. }\end{array}$ \\
\hline Link gráfico & 2 & $\begin{array}{l}\text { Significado dos Códigos e Denominações } \\
\text { As categorias de links (navegação, ajuda, comandos, etc.) representadas graficamente (ícones ou figuras) } \\
\text { precisam ser claras e diferenciáveis entre si. }\end{array}$ \\
\hline \multirow{2}{*}{ Abreviatura } & 3 & $\begin{array}{l}\text { Significado dos Códigos e Denominações } \\
\text { Explicar as abreviaturas nas páginas de alguma maneira. }\end{array}$ \\
\hline & 4 & $\begin{array}{l}\text { Legibilidade } \\
\text { Evitar o uso de abreviaturas nos menus, opções de menu, título das caixas de diálogo, e mostradores de } \\
\text { dados. }\end{array}$ \\
\hline Termo técnico & 5 & $\begin{array}{l}\text { Presteza } \\
\text { Significado dos Códigos e Denominações } \\
\text { Proporcionar definições ou descrições para os termos técnicos ou jargões empregados no site. }\end{array}$ \\
\hline $\begin{array}{l}\text { Endereço } \\
\text { Eletrônico }\end{array}$ & 6 & $\begin{array}{l}\text { Significado dos Códigos e Denominações } \\
\text { A URL da página precisa, de alguma maneira, ser compreensível. }\end{array}$ \\
\hline Informação & 7 & $\begin{array}{l}\text { Presteza } \\
\text { Colocar o endereço da página em seu rodapé. }\end{array}$ \\
\hline Objetos de controle & 8 & $\begin{array}{l}\text { Feedback Imediato } \\
\text { O sistema precisa fornecer feedback sobre as mudanças de atributos dos objetos de interação, ou seja, ao } \\
\text { selecionar um botão ou ícone correspondente a esta opção; este apresenta mudança de estado, entre visitado } \\
\text { e não visitado. }\end{array}$ \\
\hline
\end{tabular}

1) * indicação da recomendação ergonômica apresentada na ilustração da página

Conteúdo

\section{Conclusões}

4.1 Vantagens e desvantagens encontradas na aplicação da técnica

O reconhecimento das características e componentes do Website, da Homepage e do Cenário de Uso, na etapa 1 de Co-Descrição, apresentados sob forma de questões nos Formulários de Descrição Global, da Homepage e Locais, apresentou-se repetitivo quando da aplicação das tabelas de Características e Atributos relacionados aos Aspectos Ergonômicos do Website, da Homepage e do Cenário de Uso. Tais instrumentos são apresentados de formas diferentes, mas possuem o mesmo objetivo que é o de reconhecer os componentes da interface.

A participação dos projetistas e usuários é uma das maiores vantagens na aplicação da metodologia utilizada. Tal procedimento permite a comparação do prescrito pelos projetistas com o trabalho real desenvolvido pelos usuários, sendo este 
um dos fundamentos da análise ergonômica. Isto caracteriza a técnica participativa e ergonômica.

Durante as entrevistas, os usuários relataram alguns problemas na etapa de descrição das tarefas principais. Desta forma, concluiu-se que seria relevante incluir nas entrevistas, no mínimo uma questão aberta, para que eles pudessem ter a oportunidade de relatar livremente os problemas encontrados em suas ações de interação com o website e, também visando obter uma maior abrangência de tais relatos.

A confrontação dos resultados obtidos nas entrevistas entre projetistas e usuários nas questões relativas à identificação de problemas na Etapa de Descrição Assistida Local é preconizada pela técnica em sua origem. No entanto, tais questões foram apresentadas de maneira diferente nos questionários pertinentes (usuários e projetistas); inviabilizando tal comparativo que, apesar de interessante do ponto de vista descritivo, não foi realizado em virtude das próprias diferenças das questões aplicadas entre os grupos, tornando possível somente a análise isolada de cada grupo de questões. Para solucionar tal carência, sugere-se que, na referida etapa, sejam melhorados e incluídos itens idênticos ou que permitam confrontar as opiniões dos dois grupos.

Também ficou evidenciado que as inspeções via checklists, para serem realizadas, indicam a necessidade de competência e conhecimento por parte do avaliador. Desta forma, considerou-se necessário e indispensável que os avaliadores sejam especialistas em ergonomia, para que não haja perda de tempo na busca por conhecimento ergonômico e técnico dos componentes de interação da interface.

A técnica permite a inspeção dos componentes e características da interface empregando questões através de checklists, que como resultado sugerem recomendações ergonômicas aos componentes que fazem parte desta interface. Em alguns momentos estas recomendações não são geradas devido à ausência do componente na própria interface e, conseqüentemente, a não aplicabilidade de inspeção. Isto é, a partir do momento em que o componente não existe na página em avaliação, a técnica não possibilita indicações para a inclusão deste como forma de sugestão de melhoria da usabilidade. Mas, na presença do componente, são inspecionadas as questões relativas, pelas quais pôde-se concluir que as recomendações geradas avaliam tanto a utilização do componente como também permitem gerar novas possibilidades de uso do mesmo, possibilitando melhorar a qualidade de interação do usuário com a interface.

\subsection{Considerações sobre os aspectos de usabilidade do website de EaD}

A especificidade das questões da base de dados de recomendações ergonômicas permitiu, igualmente de sua parte, a identificação detalhada de problemas de usabilidade para as indicações do reprojeto do website. No que concerne à avaliação, ficou evidenciado que a inspeção se mostrou bastante abrangente. Isto, pela própria constituição da base de dados possuir um grande número de questões.

Em relação aos critérios ergonômicos, pôde-se verificar que os principais resultados para o reprojeto do website dizem respeito ao critério Condução, em especial à Presteza. Isto indica a necessidade do projetista melhorar as indicações para que o usuário possa realizar determinadas ações, pois este pode não identificar o estado ou contexto no qual se encontra, dificultando a navegação e aumentando a ocorrência de erros (ex. verificar se a ajuda geral e específica às páginas está sempre disponível ao longo do site). Os sub-critérios de Legibilidade e Feedback Imediato, também apresentaram índices consideráveis de recomendações. Além disso, o critério Carga de Trabalho, especificamente os sub-critérios Ações Mínimas e Concisão, mostraram-se 
importantes no sentido de causar o aumento da probabilidade do usuário cometer erros pelo aumento da carga de trabalho cognitivo em relação ao número de ações necessárias à realização de uma tarefa, diminuindo a eficiência do diálogo. A Concisão diz respeito à brevidade das apresentações e entradas, e as Ações Mínimas à extensão e densidade dos diálogos (ex. em páginas longas precisa existir um sumário no topo da página, ou e, um frame auxiliar permanente, que permita fazer uma navegação mais fácil aos conteúdos destas páginas). Da mesma forma, o critério Significado dos Códigos e Denominações pode sugerir operações inadequadas para o contexto, conduzindo a erros ocasionados pela codificação não significativa, dificultando a recordação e a memorização (ex. as categorias de links de navegação, ajuda, comandos, etc., representadas graficamente por ícones ou figuras, precisam ser claras e diferenciáveis entre si).

No que concerne às páginas em geral: a página da homepage, a do formulário de inscrição e a do conteúdo programático das aulas e componentes gerais do website, foram as que apresentaram o maior número de recomendações a serem atendidas. Isto indica que a interação do usuário com o website está bastante prejudicada, em função destas páginas serem essenciais para a obtenção dos objetivos para com o curso.

Quanto às recomendações sugeridas conforme as características e componentes concluiu-se que os pontos mais críticos para os componentes gerais do website encontram-se nos Recursos de Navegação e nas Animações. Porém, para a Homepage, o componente "Informação" apresentou um maior número de recomendações, indicando a necessidade de melhora na parte informacional. Para o Cenário de Uso as características/componentes que apresentaram os maiores índices referem-se aos Recursos de Navegação, ao Endereço Eletrônico, à Informação e aos Objetos de Controle. 


\section{REFERÊNCIAS}

a) BELANGER, F.; JORDAN, D. H. Evaluation and Implementation of Distance Learning Technologies, Tools and Technique. Hershey US: Ed. Idea Group Publishing, 2000, p. 7-10, 35-38, 49$53,149-150-153$

b) CYBIS, W.A.; SCAPIN, D.L.; ANDRES, D.P.; MORANDINI, M. ErgoCoin: a usability inspection tool for web sites evaluation. INRIA - Institut National de Recherche en Informatique et en Automatique, 2002.

c) CYBIS, Walter de Abreu. Uma Abordagem Ergonômica para IHC: Ergonomia de Interfaces Humano-Computador, 2000. Disponível em: <http://www.labiutil.inf.ufsc.br/apostila.htm>. Acesso em: dez. 2001.

d) CYBIS, W. A.; PIMENTA, M. S.; SILVEIRA, M. C.; GAMEZ, L. Uma Abordagem Ergonômica para o Desenvolvimento de Sistemas Interativos. In: IHC'98, 1998, Maringá.

e) GAMEZ, Luciano. Ticese - Técnica de Inspeção de Conformidade Ergonômica de Software Educacional. Originalmente apresentada como dissertação de mestrado, Universidade do Minho, Portugal, 1998.

f) ISO Draft International Standart (DIS) 92411-11 (1999), Ergonomic Requirements for officework with visual display terminals, Part 11: Guidance on Usability. International Standardization for Organization, Geneva.

g) LEUliER, C.; BASTIEN, J. M. C.; SCAPIN, D. L. Commerce \& Interactions - Compilation of Ergonomic Guidelines for the Design and Evaluation of Web Sites. Rapport. INRIA - Institut National de Recherche en Informatique et en Automatique. 1998.

h) MAYHEW, D. Software User Interface Design. Englewod Cliffs, NJ: Prentice may, 1992.

i) MCNEIL, S. G.; ROBIN, B. R.; MILLER, R. M. Facilitating interaction, communication and collaboration in online courses. Elsevier Science Ltd., Computer \& Geosciences, University of Houston, USA, 26, p. 699-708, 2000.

j) MORAES, A.; MONT'ALVÃO, C. Ergonomia - conceitos e aplicações. 2. ed. Rio de Janeiro, RJ: Ed. 2AB, 2000.

k) REED, P.; HOLDAWAY, K.; ISENSEE, S.; BUIE, E.; FOX, J.; WILLIAMS, J.; LUND, A. User interface guidelines and standarts: progress, issues, and prospects. Elsevier Science B.V., Interacting with Computers, 12, p. 119-142, 1999.

1) SHNEIDERMAN, B. Designing Information-abundant web-sites: issues and recommendations. Human-Computers Interaction Laboratories, University of Maryland, USA, 1997. Disponível em: < http://www.hbuk.co.uk/ap/ijhcs/webusability/shneiderman/shneiderman.html >. Acesso em ago. 2001. 